\title{
Electroanalytical Performance of a Carbon Paste Electrode Modified by Coffee Husks for the Quantification of Acetaminophen in Quality Control of Commercialized Pharmaceutical Tablets
}

\author{
Serge Foukmeniok Mbokou, ${ }^{1,2,3}$ Maxime Pontié, ${ }^{2,3}$ Jean-Philippe Bouchara, ${ }^{3}$ \\ Francis Merlin Melataguia Tchieno, ${ }^{1}$ Evangeline Njanja, ${ }^{1}$ \\ Assad Mogni, ${ }^{4,5}$ Pierre Yves Pontalier, ${ }^{4}$ and Ignas Kenfack Tonle ${ }^{1}$ \\ ${ }^{1}$ Electrochemistry and Chemistry of Materials, Department of Chemistry, University of Dschang, P.O. Box 67, Dschang, Cameroon \\ ${ }^{2}$ L'UNAM, University of Angers, GEPEA UMR-CNRS 6144, 2 boulevard Lavoisier, 49045 Angers, France \\ ${ }^{3}$ L'UNAM, University of Angers, GEIHP EA 3142, Institut de Biologie en Santé-IRIS, CHU, 4 rue Larrey, 49933 Angers, France \\ ${ }^{4}$ Université de Toulouse, INP-ENSIACET, Laboratoire de Chimie Agro-Industrielle (LCA), 31030 Toulouse, France \\ ${ }^{5}$ INRA, UMR 1010 CAI, 31030 Toulouse, France
}

Correspondence should be addressed to Ignas Kenfack Tonle; ignas.tonle@univ-dschang.org

Received 29 November 2015; Revised 24 February 2016; Accepted 8 March 2016

Academic Editor: Gerd-Uwe Flechsig

Copyright (C) 2016 Serge Foukmeniok Mbokou et al. This is an open access article distributed under the Creative Commons Attribution License, which permits unrestricted use, distribution, and reproduction in any medium, provided the original work is properly cited.

Electrochemical determination of acetaminophen (APAP) was successfully performed using a carbon paste electrode (CPE) modified with coffee husks (CH-CPE). Scanning electron microscopy (SEM) and SEM-energy dispersive X-ray spectroscopy (SEMEDX) were, respectively, used for the morphological and elemental characterization of coffee husks prior to their utilization. The electrochemical oxidation of APAP was investigated by cyclic voltammetry (CV), differential pulse voltammetry (DPV), and square wave voltammetry (SWV). SWV technique appeared to be more sensitive since the oxidation current of APAP was twofold higher with the $\mathrm{CH}-\mathrm{CPE}$ sensor than with the bare $\mathrm{CPE}$, in relation to the increase in the organophilic character of the electrode surface. Furthermore, on $\mathrm{CH}-\mathrm{CPE}$, the current response of APAP varied linearly with its concentration in the range of $6.6 \mu \mathrm{M}$ to $0.5 \mathrm{mM}$, leading to a detection limit of $0.66 \mu \mathrm{M}(S / N=3)$. Finally, the proposed $\mathrm{CH}$-CPE sensor was successfully used to determine the amount of APAP in commercialized tablets (Doliprane ${ }^{\circledR} 500$ and Doliprane 1000), with a recovery rate ranging from $98 \%$ to $103 \%$. This novel sensor opens the way for the development of low-cost and reliable devices for the electroanalysis of pharmaceutical formulations in developing countries.

\section{Introduction}

Acetaminophen $\left(4^{\prime}\right.$-hydroxyacetanilide or $\mathrm{N}$-acetyl $p$-aminophenol, hereafter referred to as APAP) is one of the most worldwide used drugs, because of its great activity against mild to moderate pains associated with headache, backache, and arthritis [1] and its efficiency in relieving fever [2]. Generally, APAP does not exhibit any harmful side effect but hypersensitivity or overdose ingestion in few cases leads to the formation of toxic metabolites that can cause severe nephrotoxicity and hepatotoxicity $[3,4]$, accompanied in some cases by renal failure $[5,6]$. Traditional analytical methods used for the determination of APAP include titrimetry [7], UV-visible spectrophotometry [8-10], spectrofluorometry [11], chemiluminescence [12], and chromatography [13-15]. Although these methods operate quite well, they are generally timeconsuming and laborious. Moreover, they are not convenient for the detection of APAP at very low concentrations. As alternatives, electrochemical methods offer several advantages in terms of cost, accuracy, selectivity, and sensitivity [1618]. The resort to electroanalytical methods is also afforded by the electroactive character of APAP which can be easily 
oxidised in proper conditions due to the phenolic, hydroxyl, and amino groups that it contains on its aromatic ring. During the past few years, many works have been focused on the electrochemical determination of APAP. Some recent reports on its quantification by means of chemically modified electrodes include the use of a gold nanoparticles/multiwalled carbon nanotube/glassy carbon electrode [19] or a borondoped diamond electrode modified with Nafion $\left.{ }^{(}\right)$and lead films [20] and the exploitation of a poly(thionine)-carbon nanotube modified carbon film electrode [21]. Likewise, carbon paste electrodes (CPEs) chemically modified by an active compound and/or material displaying affinity towards APAP have been shown to be useful tools for the detection of APAP. As typical examples, Beitollahi and Nekooei [22] reported the use of a carbon paste electrode modified with $\mathrm{CuO}$ nanoparticles to simultaneously determine APAP and other drugs. In the same lines, a sensor based on a carbon paste electrode modified with (E)-2-((2-chlorophenyl imino)methyl)benzene-1,4-diol (CD) and titanium dioxide nanoparticles was successfully prepared by Mohammad et al. [23]. Shahmiri et al. [24] reported a simple and rapid method for the analysis of APAP and glutathione, based on a CPE modified by ethynylferrocene and NiO/MWCNT nanocomposite. More recently, CPEs chemically modified with $\mathrm{TiO}_{2}$ nanoparticles [25], poly(glycine) [26], and $\mathrm{Fe}(\mathrm{III})$ clinoptilolite nanoparticles [27] have been applied as electroanalytical devices for the voltammetric determination of APAP. These last mentioned studies demonstrate that CPE introduced in electroanalysis in 1958 by Adams [28] remains to date a convenient device for the qualitative and quantitative analyses of various compounds. CPEs are easy to prepare, are inexpensive, and generally give rise to reproducible signals [29]. Also, they display low background and long term stability, as well as high polarization limits in both anodic and cathodic directions [30]. Taking into consideration these features, the development of low-cost, simple, and accurate electrochemical sensors for the detection of APAP is of permanent interest for quality control analysis of pharmaceutical formulations and for medical control in biological fluids as serum or plasma.

On the other hand, the exploitation of lignocellulosic materials (LCMs) as effective sorbents for organic compounds such as dyes and pesticides has been largely investigated during the last decade [31-34]. The uptake of such organic compounds is commonly achieved via hydroxyl and carbonyl groups found abundantly in polysaccharides (cellulose and hemicelluloses) and lignin, which together constitute about $90 \%$ of dried LCMs [35]. Their attractiveness results from their great availability, low cost, biodegradability, and organophilic character. Coffee, one of the most popular beverages in the world, is cultivated in about 80 countries across the globe [36]. In the western region of Cameroon, two main varieties of coffee are largely produced: Coffea arabica and Coffea robusta. Their transformation generates large amounts of by-products such as coffee husks that are obtained when coffee berries are processed by the drying method [36]. Coffee husk is the part enclosing coffee beans; it represents about $12 \%$ of the berry dry weight. Usually, it contains cellulose, hemicellulose, lignin, and ash [37]. This attractive composition reasonably suggests that, as LCM, coffee husks could be exploited either as sorbent for various compounds or as effective electrode modifier in the field of amperometric sensors.

In the present work, a simple, reliable, and fast procedure was developed for the determination of acetaminophen by square wave voltammetry, based on a CPE. It is worth mentioning that the use of coffee husks rather than carbon nanotubes [38] or $\mathrm{ZrO}_{2}$ nanoparticles [39] as CPE electrode modifiers, and even rather than some other carbon based electrodes [40-42], has led to a more sensitive device towards the detection of APAP. Although there are many reports of voltammetric APAP sensors with lower limit of detection, the method proposed herein has some advantages since the prepared $\mathrm{CH}-\mathrm{CPE}$ is sufficiently sensitive for its intended purpose which is the analysis of pharmaceutical formulations. Moreover, it is inexpensive, is easy to fabricate, and was found to be suitable for determination of APAP without interference from sample matrices.

Prior to the assessment of coffee husks as electrode modifier, their macromolecular composition was determined using the Acid-Detergent Fiber- (ADF-) Neutral Detergent Fiber (NDF) method. The surface of the obtained electrode was characterized using scanning electron microscopy and cyclic voltammetry. Finally, the analytical performance of the proposed $\mathrm{CH}-\mathrm{CPE}$ for the quantification of APAP was evaluated by square wave voltammetry (SWV) in commercial pharmaceutical tablets.

\section{Materials and Methods}

2.1. Reagents. Acetaminophen (APAP) was purchased from Aldrich as powder and used as received. $0.1 \mathrm{M}$ phosphate buffer solution ( $\mathrm{pH}$ 7.4) (PBS) was used as supporting electrolyte. All other aqueous solutions were prepared from analytical grade chemicals, using deionized water obtained from an Elga LabWater ultrapure-water system (Purelab-UVUF, Elga, France) ( $\mathrm{pH} 6.5$, conductivity $<1 \mu \mathrm{S} \mathrm{cm}^{-1}$, and TOC $<0.1 \mathrm{M}$ ). Doliprane 500 and Doliprane 1000 tablets (manufactured in February 2014) were purchased from SanofiAventis (France) and delivered under batch number 5768.

2.2. Coffee Husks. Coffee husks used in this study were collected from a coffee-processing mill in Santchou (Menoua Division, West Cameroon) and dried under sunlight for 3 days. They were ground and crushed, and a series of sieves allowed obtaining their fine fraction $(0-100 \mu \mathrm{m}$ mean average size used for the preparation of the modified carbon paste electrode).

2.3. Apparatus. The electrochemical measurements were performed using an electrochemical analyzer PG580 (Uniscan Instruments, UK) connected to a personal computer. The electrochemical software used was UiEchem version 3.27, from Uniscan Instruments. A classical three-electrode cell configuration was employed, consisting of bare or modified CPEs serving as working electrodes, a saturated calomel reference electrode (SCE), and a platinum wire counter electrode. 
2.4. Preparation of CPEs. The unmodified CPE was prepared by thoroughly hand mixing $30 \mathrm{mg}$ of silicone oil with $70 \mathrm{mg}$ of graphite powder (analytical grade, ultra F, $<325$ mesh, from Alfa) in a mortar. A portion of the composite mixture was packed into the cylindrical hole of a Teflon ${ }^{\circledR}$ tube equipped with a copper wire serving as electrical contact with the rest of the circuit. The surface exposed to the solution was polished on a weighing paper to give a smooth aspect before use. Coffee husks modified carbon paste electrodes $(\mathrm{CH}-$ CPEs) were prepared as described for the bare CPE by using $65 \mathrm{mg}$ of graphite powder, $30 \mathrm{mg}$ of silicone oil, and $5 \mathrm{mg}$ of coffee husks powder. For comparison purposes, a third electrode was prepared with the following composition: $65 \mathrm{mg}$ of graphite powder, $30 \mathrm{mg}$ of silicone oil, and $5 \mathrm{mg}$ of pure cellulose; it is referred to as Ce-CPE throughout the text. When not in use, the CPEs were removed from supporting electrolyte and kept at room temperature.

2.5. Other Procedures. For the determination of APAP in pharmaceutical formulations, each commercial tablet was carefully weighed, then finely powdered, and dissolved in $1 \mathrm{~L}$ PBS. A $1.25 \mathrm{~mL}$ aliquot of this solution was then diluted to the mark with PBS in a $50 \mathrm{~mL}$ volumetric flask. The samples were finally spiked with known amounts of APAP and the concentration of APAP in solution was determined using the standard addition method.

Morphological analysis of CPE surface was achieved by Field Emission Gun Scanning Electron Microscopy (FEGSEM) on a JSM-6301F apparatus from JEOL (SCIAM, University of Angers, France). The coffee husk powder was immobilized on a SEM sample holder using adhesive carbon tape. Images obtained were from secondary electrons of $3 \mathrm{keV}$, with magnifications between $\times 25$ and $\times 20,000$. For energy dispersive X-ray spectroscopy (EDX) experiments conducted on the same equipment, the beam energy was $20 \mathrm{keV}$.

An estimation of the three parietal constituents (cellulose, hemicellulose, and lignin) contained in the coffee husks was made using the ADF-NDF method of Van Soest and Wine $[46,47]$. Solubility in the ADF, NDF, and ADF- $\mathrm{KMnO}_{4}$ solutions was also extrapolated. Solubilisation and filtration were done in a Fibertec M2 system, equipped with a heating and reflux device (from FOSS, France). All determinations were carried out in duplicate.

The contact angle measurements were performed on the unmodified $\mathrm{CPE}$ and modified $\mathrm{CH}-\mathrm{CPE}$ by the sessile drop technique which allows comparison between materials. In this aim, the electrodes were freshly prepared and dried at room temperature in a desiccator tank. After complete drying, a droplet of ultrapure water $(20 \mu \mathrm{L})$ was deposited onto the CPE surface by means of a microsyringe and the contact angle of the droplet with the surface was measured with a KRÜSS DSA30 contact angle meter. Reported values are the average contact angle of 3 droplets. During the short measurement time (less than 1 minute), no change in contact angle was observed. A variation of 2 degrees in the angle was considered significant.

For the evaluation of the real surface area of the electrodes, $\mathrm{CPE}, \mathrm{CH}-\mathrm{CPE}$, and Ce-CPE were used to record by cyclic voltammetry the curves of a $5 \mathrm{mM}\left[\mathrm{Fe}(\mathrm{CN})_{6}\right]^{3-}$ solution in $0.1 \mathrm{M} \mathrm{PBS}$ ( $\mathrm{pH}$ 7.4). The peak intensity $\left(I_{p}\right)$ of the analyte at a given electrode can be used to determine the real surface area $(A)$ of that electrode on the basis of RandlesSevcik equation: $I_{p}=k \cdot n^{3 / 2} \cdot A \cdot D^{1 / 2} \cdot C \cdot v^{1 / 2}$, where $k=$ $2.69 \times 10^{5}, n$ is the number of moles of electrons transferred per mole of electroactive species, $A\left(\mathrm{~cm}^{2}\right)$ is the area of the electrode, $D\left(\mathrm{~cm}^{2} \mathrm{~s}^{-1}\right)$ is the diffusion coefficient of the electroactive species, $C\left(\mathrm{~mol} \mathrm{~L}^{-1}\right)$ is the bulk concentration of the electroactive species, and $v\left(\mathrm{~V} \mathrm{~s}^{-1}\right)$ is the potential scan rate [48].

\section{Results and Discussion}

3.1. SEM and EDX Characterization of Different Electrodes. The SEM 2D images of the bare CPE and CH-CPE are shown in Figure 1. As can be seen, no significant difference was observed on the surfaces of both electrodes. Nevertheless, they can be differentiated by the aspect of carbon paste. Unmodified CPE has shown a plate-like aspect, while $\mathrm{CH}$ $\mathrm{CPE}$ shows a different aspect in relation to the presence of coffee husk powder, which is essentially constituted by cellulose, lignin, and hemicellulose fibers.

To ascertain the presence of coffee husks within the modified CPE, EDX experiments were performed and the response obtained by difference between the EDX spectra of the bare CPE and CH-CPE is presented in Figure 1(c). According to the literature data, lignocellulosic materials are essentially constituted of cellulose, hemicelluloses, and lignin [43]. They can also contain extractible matter ( 2 to $8 \%$ of dry matter), metallic cations such as $\mathrm{Mg}^{2+}, \mathrm{Ca}^{2+}, \mathrm{K}^{+}$, and $\mathrm{Na}^{+}$, and other chemical elements like P, N, S, or Si [43, 49]. As expected, the obtained EDX spectrum in Figure 1(c) revealed the presence of $\mathrm{K}, \mathrm{Ca}, \mathrm{O}, \mathrm{Na}, \mathrm{Mg}, \mathrm{Si}, \mathrm{P}$, and $\mathrm{S}$ in relation to the presence of coffee husk powder in modified electrode. The percentages of cellulose, lignin, and hemicellulose in the coffee husk powder were determined using the ADF-NDF method. Cellulose and lignin accounted for $55.1 \%$ and $9.2 \%$ of the total dry weight, a composition which is different from that reported for coffee husks from Ethiopia [37] where it has been found to be $24.5 \%$ of cellulose and an equal amount of lignin (23.7\%). However, the chemical composition of coffee and coffee husks varies from one country to another, and within a country it depends on geographic location, climate, age, and soil condition [36]. For instance, our results are in close agreement with those reported in another study performed in Portugal [50], where it was found to be $43.0 \%$ of cellulose and $9.0 \%$ of lignin.

3.2. Sessile Drop Contact Angle Measurements. The organophilic character of CPEs was evaluated using sessile drop contact measurements. A progressive decrease was observed in contact angle from $106^{\circ} \pm 1^{\circ}$ for the bare CPE to $89^{\circ} \pm$ $1^{\circ}$ for $\mathrm{CH}-\mathrm{CPE}$ and $75^{\circ} \pm 1^{\circ}$ for Ce-CPE, along with the increase in the cellulose content in the carbon paste. These results therefore demonstrated a decrease in the hydrophobic character of the electrode surface due to the presence of cellulose, a well-known hydrophilic matter, at the surface of Ce-CPE, or of coffee husks which contain a high amount 


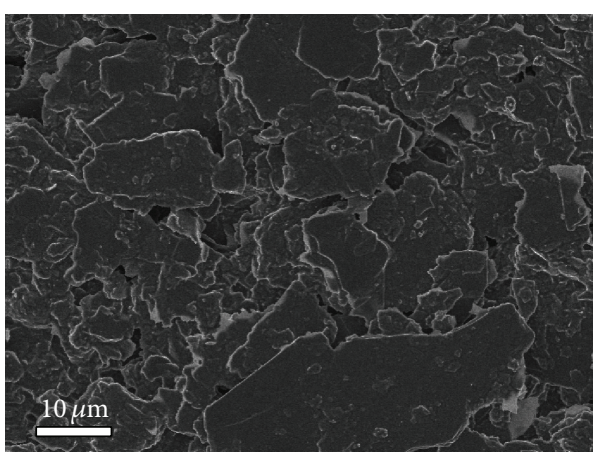

(a)

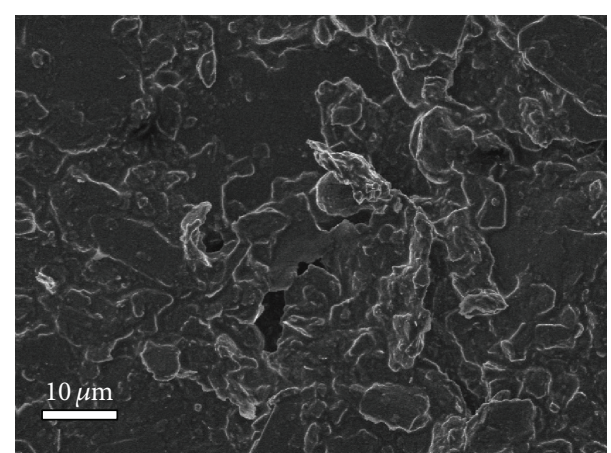

(b)

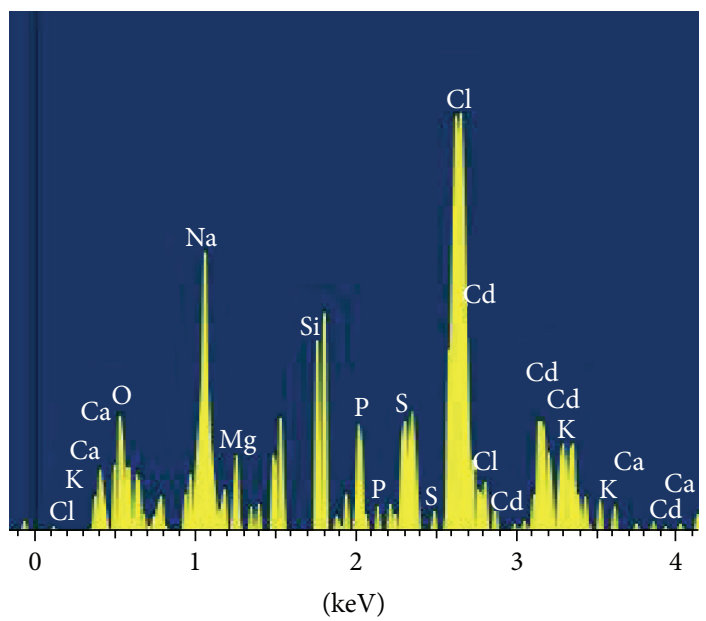

(c)

Figure 1: 2D-SEM images of (a) bare CPE and (b) CH-CPE. (c) EDX spectrum obtained by difference between EDX spectra of the bare CPE and $\mathrm{CH}-\mathrm{CPE}$.

of cellulose, at the surface of $\mathrm{CH}-\mathrm{CPE}$. From these data, one may speculate a higher sensitivity of $\mathrm{CH}-\mathrm{CPE}$ and $\mathrm{Ce}-$ CPE regarding the uptake of APAP, in comparison with the unmodified electrode, since there is a relationship between the sensitivity of electrodes and the hydrophilic character of their surface [51].

3.3. Determination of Geometric and Real Surfaces of Unmodified CPE, CH-CPE, and Ce-CPE. To measure the electrochemically active surface areas of $\mathrm{CPE}$ and $\mathrm{CH}-\mathrm{CPE}$, a third electrode was prepared which contained pure cellulose as modifier (Ce-CPE). The geometric surfaces of these electrodes were calculated using the formula $S=\pi r^{2}$, where $\pi=3.14$ and $r=15 \mathrm{~mm}$ which is the geometric radius $(r)$ of the electrodes. Thus, the geometrical areas $A$ of the tested electrodes were $0.071 \mathrm{~cm}^{2}$. By contrast, the electrochemically active surface areas of $\mathrm{CPE}, \mathrm{CH}-\mathrm{CPE}$, and Ce-CPE were evaluated from the current density obtained for each electrode using cyclic voltammetry. The observed peak current, given by the Randles-Sevcik equation (see Section 2.5), was applied to derive the real surface area of the investigated working electrodes. Using the following data: $n=2, D=0.62 \times 10^{-5} \mathrm{~cm}^{2} \mathrm{~s}^{-1}, C=5 \mathrm{mM}$, and $v=0.1 \mathrm{~V} \mathrm{~s}^{-1}$, the obtained surfaces were $0.082 \pm 6.7 \times 10^{-6} \mathrm{~cm}^{2}, 0.097 \pm$
$6.6 \times 10^{-6} \mathrm{~cm}^{2}$, and $0.141 \pm 3.2 \times 10^{-6} \mathrm{~cm}^{2}$ for the bare CPE, $\mathrm{CH}-\mathrm{CPE}$, and Ce-CPE, respectively. Yet, the current densities obtained were $J_{\mathrm{pa}}=(10.568 \pm 0.675) \times 10^{-4}$ for the bare CPE, $J_{\mathrm{pa}}=(10.887 \pm 0.680) \times 10^{-4}$ for $\mathrm{CH}-\mathrm{CPE}$, and $J_{\mathrm{pa}}=(30.125 \pm$ $0.956) \times 10^{-4} \mu \mathrm{A} \mathrm{cm}^{-2}$ for Ce-CPE. One can reasonably assign the observed differences to modifiers (coffee husks and cellulose) which have improved the organophilic character of the electrodes, thereby increasing the amount of APAP chemically transformed at these electrodes.

The three electrodes were then used to record by cyclic voltammetry the signal of a $75 \mathrm{mg} \mathrm{L}^{-1}$ APAP solution in PBS (curves not shown). The ratios of peak intensities and of real surface areas obtained with modified CPEs, in relation to the bare $\mathrm{CPE}$, are reported in Table 1 . One can notice that the peak current is influenced by the percentage of cellulose in the carbon paste: the oxidation peak intensity of APAP depends on physical effect (i.e., the increase of the real surface area) and on chemical effect (i.e., the hydrophilic character of coffee husks).

3.4. Electrochemical Impedance Spectroscopy (EIS). EIS is an accurate tool for determination of the electrical properties of an electrode/electrolyte interface. It was used to analyze the charge transfer rate for both bare CPE and coffee husks 
TABLE 1: Ratios of real surface areas and of peak intensities.

\begin{tabular}{lccc}
\hline Electrodes & $\begin{array}{c}\text { Ratio of } I_{p} \text { with modified } \\
\text { electrodes versus bare CPE }\end{array}$ & $\begin{array}{c}\text { Ratio of real surface areas of modified } \\
\text { electrodes versus bare CPE }\end{array}$ & $\begin{array}{c}\text { Chemical effect } \\
\text { (hydrophilic character of } \\
\text { cellulose) }\end{array}$ \\
\hline $\mathrm{CPE}$ & 1 & 1 & 0 \\
$\mathrm{CH}-\mathrm{CPE}$ & 2.000 & 1.182 & 0.820 \\
$\mathrm{Ce}-\mathrm{CPE}$ & 2.600 & 1.719 & 0.881 \\
\hline
\end{tabular}

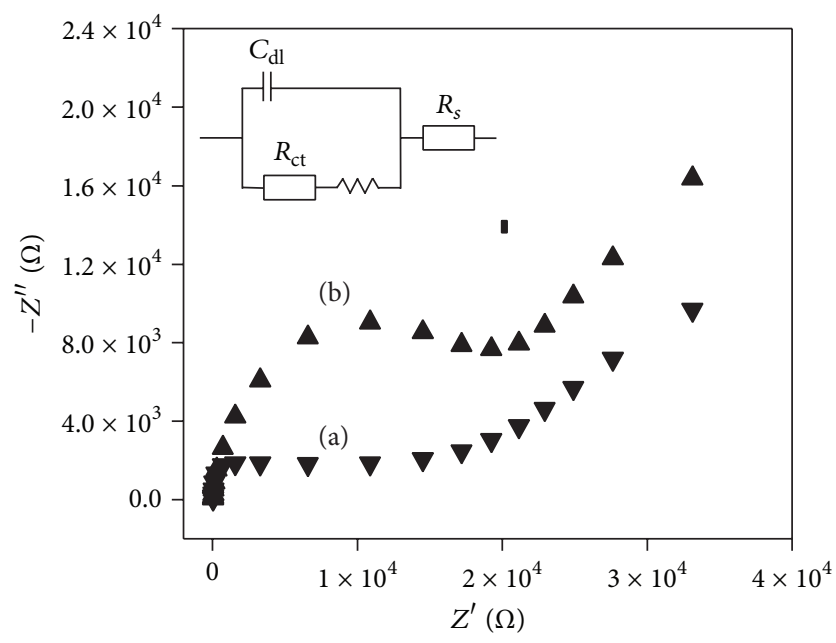

Figure 2: Nyquist plots of (a) CPE and (b) CH-CPE obtained in $5 \mathrm{mM}\left[\mathrm{Fe}(\mathrm{CN})_{6}\right]^{3-/ 4-}(1: 1)$ solution containing $0.1 \mathrm{M}$ PBS (pH 7.4). The frequency range was from 0.1 to $10^{4} \mathrm{~Hz}$ at the formal potential of $0.18 \mathrm{~V}$.

modified CPE. Figure 2 shows the Nyquist diagrams of $5 \mathrm{mM}\left[\mathrm{Fe}(\mathrm{CN})_{6}\right]^{3-/ 4-}$ recorded in $0.1 \mathrm{M} \mathrm{PBS}(\mathrm{pH} 7.4)$ on the unmodified $\mathrm{CPE}$ and $\mathrm{CH}-\mathrm{CPE}$, in the ac frequency range from $0.1 \mathrm{~Hz}$ to $10.0 \mathrm{kHz}$.

A marked difference was observed between the bare $\mathrm{CPE}$ (Figure 2(a)) and $\mathrm{CH}-\mathrm{CPE}$ with a fourfold increase in the interface electron transfer resistance $\left(R_{\mathrm{ct}}=6\right.$ and $25 \mathrm{k} \Omega$, resp.). This was attributed to the presence of coffee husks in the bulk of CPE that introduced a resistance at the electrode/solution interface, leading thereby to a lower rate of electron transfer for the $\left[\mathrm{Fe}(\mathrm{CN})_{6}\right]^{3-/ 4-}$ redox system. This fact also demonstrated that coffee husks were successfully immobilized on the CPE surface.

3.5. Electrochemical Behavior of APAP and Effect of Scan Rate. APAP bears hydroxyl and amine functional groups in its structure, and it is expected that acidity of the supporting electrolyte could affect its redox behavior. Cyclic voltammetry was used to investigate the electrochemical behavior of APAP on the bare CPE. Since the proposed sensor is devoted to the analysis of APAP in pharmaceutical formulations, $0.1 \mathrm{M}$ phosphate buffer solution (PBS) was chosen as supporting electrolyte to meet physiological conditions. Thus, the influence of $\mathrm{pH}$ on the oxidation peak current of APAP was investigated in acidic, neutral, and basic media, that is, in $0.1 \mathrm{M}$ PSB with $\mathrm{pH}$ fixed at 5.5, 7.4, and 8.6. As shown in Figure S1 (Supporting Information, in Supplementary Material available

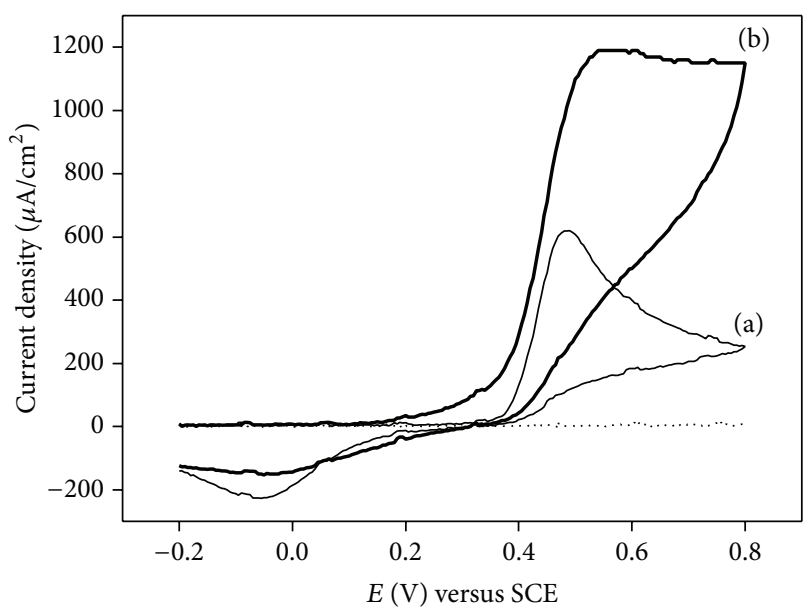

FIgUre 3: Cyclic voltammograms of $75 \mathrm{mg} \mathrm{L}^{-1} \mathrm{APAP}$ in PBS at the (a) bare CPE and at (b) CH-CPE. Potential scan rate: $100 \mathrm{mV} \mathrm{s}^{-1}$.

online at http://dx.doi.org/10.1155/2016/1953278), 0.1 M PBS at $\mathrm{pH} 7.4$ gave rise to the best signal in terms of peak shape and peak intensity. It was selected as convenient supporting electrolyte and used for subsequent experiments. Afterwards, the behavior of APAP was investigated on coffee husks modified CPE. Figure 3 compares the cyclic voltammetric signals of APAP recorded on the bare $\mathrm{CPE}$ or on $\mathrm{CH}$ CPE. An anodic peak was observed at $440 \mathrm{mV}$ versus SCE, which corresponded to a second weak reduction peak at $-110 \mathrm{mV}$. Both peaks are associated with a redox process corresponding to the oxidation of APAP leading to N-acetylpara-benzoquinone imine (NAPQI) [52-55] as illustrated by Scheme 1.

The corresponding current density was found to be $600 \mu \mathrm{A} \mathrm{cm}^{-2}$ (Figure 3(a)). When the unmodified CPE was replaced by $\mathrm{CH}-\mathrm{CPE}$, a more intense peak was obtained characterized by a current density of ca. $1200 \mu \mathrm{A} \mathrm{cm}^{-2}$ (Figure 3(b)). This could be assigned to the presence of coffee husks in $\mathrm{CH}-\mathrm{CPE}$ that increases the real surface area and improves the organophilic character of the modified electrode.

To yield more information about the behavior of APAP on $\mathrm{CH}-\mathrm{CPE}$, the effect of scan rate $(v)$ on the oxidation and reduction peaks was investigated by cyclic voltammetry. As shown in Figure 4(a), the anodic and cathodic peak signals increased with the scan rate in the range from 50 to $250 \mathrm{mV} \mathrm{s}^{-1}$ and no catalytic effect was observed.

Moreover, the relationship between the peak currents (anodic and catholic) and the square root of $v$ was linear (Figure 4(b)) and expressed by the following equations: 


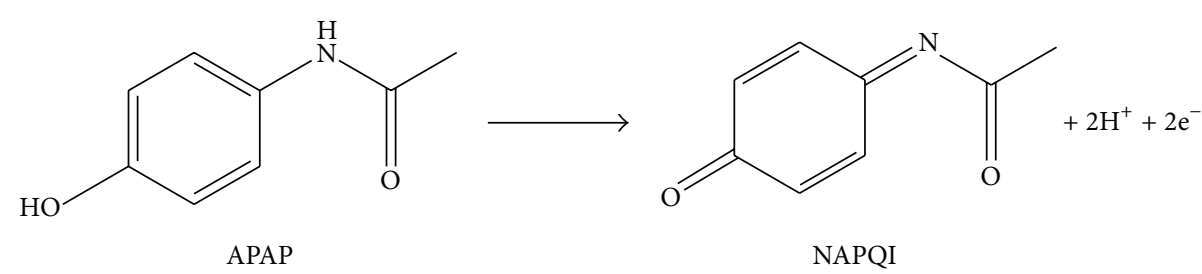

SCHEME 1: Electrochemical oxidation of APAP.

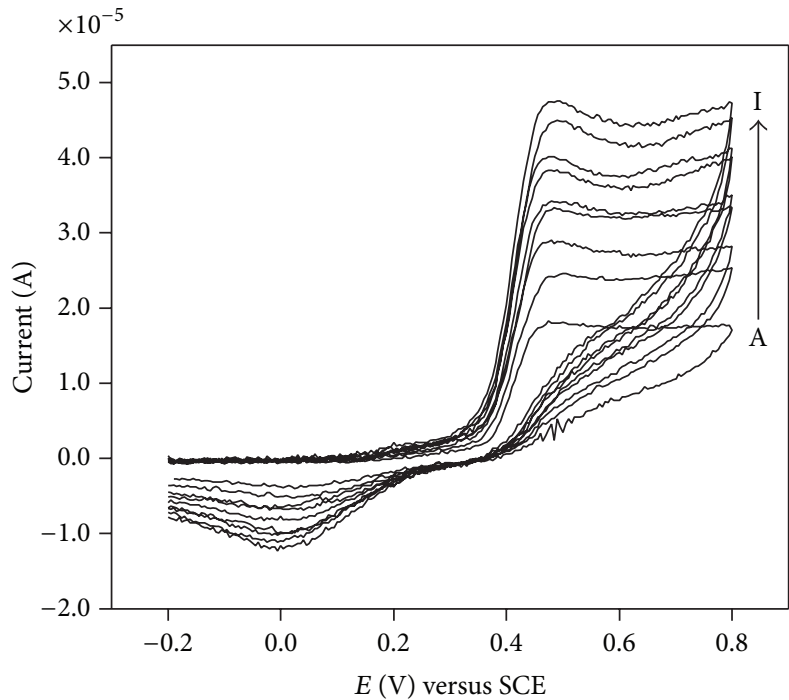

(a)

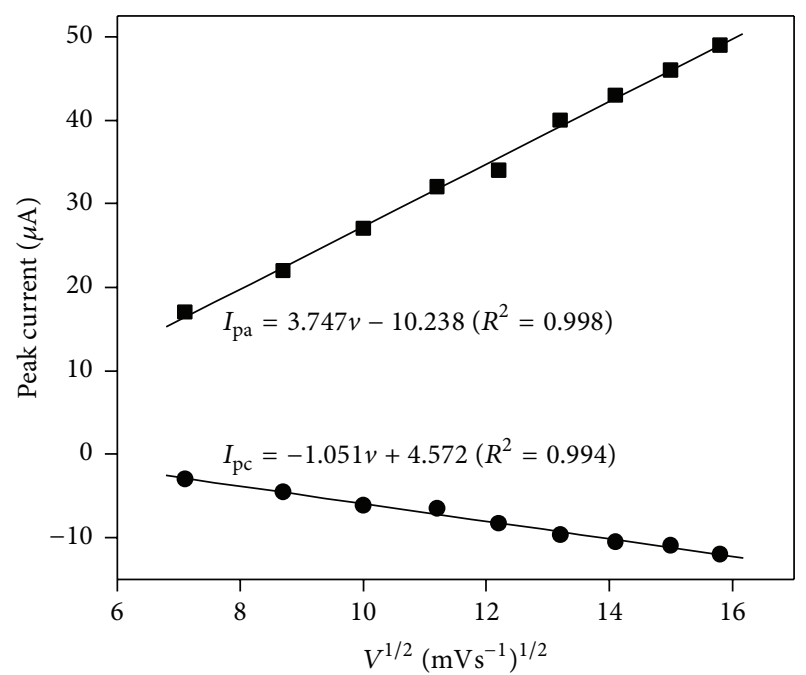

(b)

Figure 4: (a) CV curves recorded on CH-CPE with $25 \mathrm{mg} \mathrm{L}^{-1}$ APAP in PBS at different scan rates from 50 to $250 \mathrm{mV} \mathrm{s}^{-1}$. (b) Linear relationship between the electrode responses and the square root of the potential scan rate.

$I_{\mathrm{pa}}(\mu \mathrm{A})=3.747 v^{1 / 2}\left(\mathrm{mV} \mathrm{s}^{-1}\right)-10.238\left(R^{2}=0.998\right)$ and $I_{\mathrm{pc}}$ $(\mu \mathrm{A})=-1.051 v^{1 / 2}\left(\mathrm{mV} \mathrm{s}^{-1}\right)+4.572\left(R^{2}=0.994\right)$.

These results indicate that a diffusion controlled process takes place at the electrode, which is the mass transport rate of APAP to the surface of the electrode across a concentration gradient. It clearly appears that the presence of coffee husks increases the oxidation peak intensity of APAP corresponding to a good sensitivity of the modified electrode. These results open the way for further development of a sensor for APAP determination.

3.6. Comparison between SWV and DPV Techniques towards the Behavior of APAP. Prior to the optimization of the sensor based on $\mathrm{CH}-\mathrm{CPE}$, the stripping currents of a solution of $75 \mathrm{mg} \mathrm{L}^{-1}$ APAP were recorded in PBS using SWV and differential pulse voltammetry (DPV). The obtained results, presented in Figure 5, show the higher sensitivity of SWV compared with DPV.

The operating parameters of both techniques were optimized in order to reach maximum electroanalytical sensitivity, following the methodology reported by Pontié et al. [51]. The SWV optimized parameters were frequency $400 \mathrm{~Hz}$, pulse height $90 \mathrm{mV}$, and scan increment $15 \mathrm{mV}$, while the DPV optimized parameters were pulse width $20 \mathrm{~ms}$, step time $30 \mathrm{~ms}$, pulse height $180 \mathrm{mV}$, and scan increment $20 \mathrm{mV}$.
Considering the inherent advantages of SWV such as minimization on the contribution from the capacitive charging current to the current signal as reported elsewhere [56, 57], it was further used to develop the sensor proposed in this study for the determination of APAP. This was also guided by the well-defined voltammograms exhibited by APAP (Figure 5), in addition to the higher sensitivity of this method compared to DPV.

3.7. Calibration Curve. The oxidation peak current of APAP was directly proportional to its concentration (Figure 6) over the range from $6.6 \mu \mathrm{M}$ to $0.5 \mathrm{mM}$. The corresponding calibration curve (inset in Figure 6) followed the linear regression equation: $I_{p}(\mu \mathrm{A})=0.63 C\left(\mu \mathrm{mol} \mathrm{L}^{-1}\right)-1.4\left(R^{2}=\right.$ 0.998).

The detection limit (DL) calculated with a signal-to-noise ratio of 3 was found to be $0.66 \mu \mathrm{M}$. A comparison of the results for the voltammetric determination of APAP using other modified CPEs reported in the literature is given in Table 2.

It can be seen that the detection limit obtained in the present study $(0.66 \mu \mathrm{M})$ is close to $[22,44]$ or even better than those achieved with CPEs incorporating gold nanoparticles [53], graphene oxide [44], or carbon nanotubes [38, 45] as main modifiers. One advantage of the present approach is 
TABLE 2: Comparison of detection limits (DLs) of different modified CPEs reported for the detection of APAP.

\begin{tabular}{|c|c|c|c|c|}
\hline Modified electrodes & $\mathrm{pH}$ & Linear range $(\mu \mathrm{M})$ & $\mathrm{DL}(\mu \mathrm{M})$ & Reference \\
\hline $\begin{array}{l}\text { Ethynylferrocene-NiO/MWCNT } \\
\text { nanocomposite modified CPE }\end{array}$ & 6 & $0.8-600$ & 0.500 & {$[22]$} \\
\hline CPE modified with CNT and PAP & 5 & $10-100$ & 1.1 & [38] \\
\hline $\mathrm{ZrO}_{2}$ nanoparticles-modified CPE & 7 & $1.0-2500$ & 0.912 & {$[39]$} \\
\hline $\begin{array}{l}\text { Graphene- } \mathrm{CoFe}{ }_{2} \mathrm{O}_{4} \text { nanocomposite } \\
\text { modified } \mathrm{CPE}\end{array}$ & 7 & $0.03-12$ & 0.025 & [43] \\
\hline PEDOT graphene oxide composites & 4.8 & $10-1000$ & 0.57 & [44] \\
\hline Carbon nanotube modified CPE & 7 & $1-1000$ & 0.46 & [45] \\
\hline CPE modified by coffee husks & 7.4 & $6.6-500$ & 0.66 & This work \\
\hline
\end{tabular}

PEDOT: poly(3,4-ethylenedioxythiophene); PAP: poly(3-aminophenol).

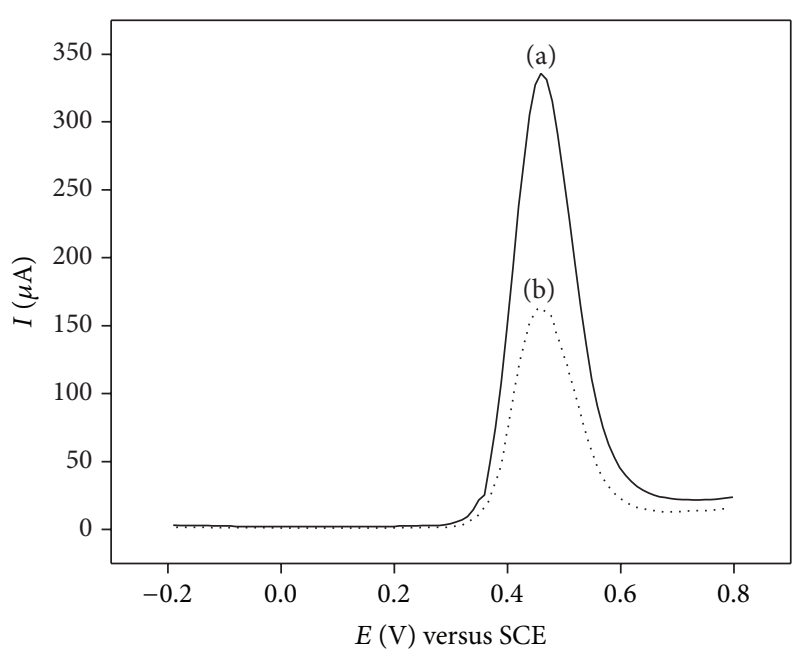

FIGURE 5: SWV and DPV curves obtained at CH-CPE in $75 \mathrm{mg} \mathrm{L}^{-1}$ APAP in PBS (potential scan rate: $100 \mathrm{mV} \mathrm{s}^{-1}$ ).

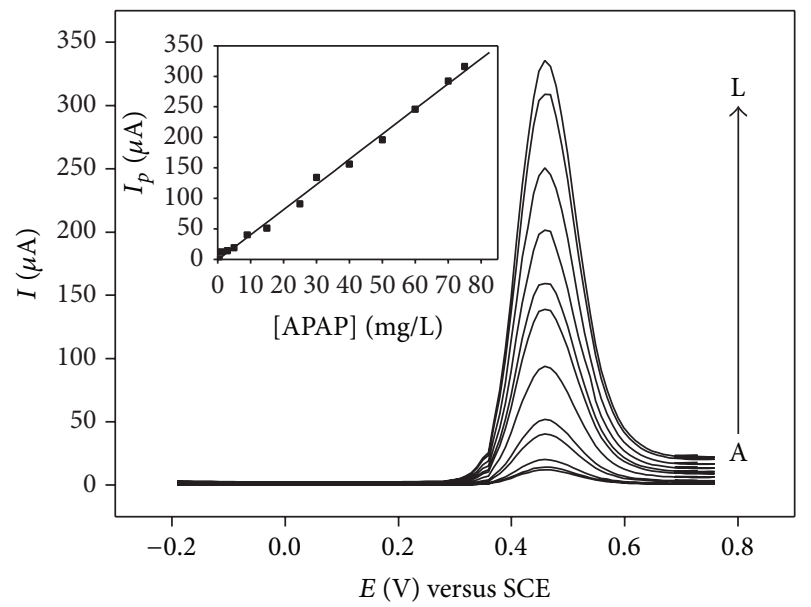

FIGURE 6: SWV of APAP at different concentrations in PBS on the CH-CPE. APAP concentration (A-L): 1, 3, 5, 9, 15, 25, 35, 40, $50,60,70$, and $75 \mathrm{mg} \mathrm{L}^{-1}$. Insert shows peak current versus APAP concentration.

that the electrochemical device is based on an inexpensive material (coffee husks), conversely to other materials used as electrode modifiers.
TABLE 3: Effect of potential interfering species on the response of $\mathrm{CH}-\mathrm{CPE}$ to $25 \mathrm{mg} \mathrm{L}^{-1}$ APAP in PBS.

\begin{tabular}{|c|c|c|}
\hline $\begin{array}{l}\text { Interfering } \\
\text { species }\end{array}$ & $\begin{array}{c}\text { Concentration } \\
\left(\mathrm{mg} \mathrm{L}^{-1}\right) \text { of added } \\
\text { species }\end{array}$ & $\begin{array}{l}\text { \% variation in the SWV } \\
\text { peak current (with } I_{\mathrm{APAP}} \\
=100 \%)\end{array}$ \\
\hline \multirow{4}{*}{ Hydroquinone } & 25 & +3.2 \\
\hline & 50 & +4.9 \\
\hline & 75 & +14.2 \\
\hline & 100 & +20.2 \\
\hline \multirow{4}{*}{$\begin{array}{l}\text { Para- } \\
\text { aminophenol }\end{array}$} & 25 & 0 \\
\hline & 50 & +3.5 \\
\hline & 75 & +7.8 \\
\hline & 100 & +10.3 \\
\hline \multirow{4}{*}{ Dopamine } & 25 & -3.5 \\
\hline & 50 & -5.1 \\
\hline & 75 & -12.5 \\
\hline & 100 & -20.6 \\
\hline \multirow{4}{*}{ Ascorbic acid } & 25 & 0 \\
\hline & 50 & +4.8 \\
\hline & 75 & +9.4 \\
\hline & 100 & +13.2 \\
\hline \multirow{3}{*}{ Aspartic acid } & 25 & -10.3 \\
\hline & 50 & -20.5 \\
\hline & 75 & -45.3 \\
\hline \multirow{3}{*}{ Glucose } & 25 & -6.0 \\
\hline & 50 & -12.0 \\
\hline & 75 & -20.6 \\
\hline
\end{tabular}

3.8. Interference Study. The influence of some electroactive species that commonly coexist in physiological fluids was investigated under the optimal experimental conditions defined above. The selected potential interfering species were hydroquinone, para-aminophenol, dopamine, ascorbic acid, aspartic acid, and glucose. The tolerance limit for each compound was considered the maximum concentration which caused approximately $\pm 5 \%$ relative error in the determination of APAP. Thus, known amounts of each of these species were added to a $25 \mathrm{mg} \mathrm{L}^{-1}$ APAP solution and the obtained solutions were analyzed by SWV. Results are summarized in Table 3 (see Figure S2, Supporting Information, for typical curves recorded).

The presence of up to 2-fold excess of hydroquinone, para-aminophenol, dopamine, and ascorbic acid in the APAP 
TABLE 4: Determination of APAP in commercial tablets using CH-CPE (all values are in mg, except for recovery rate in \%).

\begin{tabular}{ccc}
\hline & Tablet initial mass & $1080 \pm 1$ \\
& & $1076 \pm 1$ \\
& Tablet mass obtained after powdering & \\
$996 \pm 30$ & $1020 \pm 20$ \\
& Theoretical APAP mass in the weighted tablet & $102 \pm 3$ \\
& APAP mass determined with CH-CPE & $602 \pm 1$ \\
& Recovery (\%) & $597 \pm 1$ \\
& Tablet initial mass & $496 \pm 15$ \\
& Tablet mass obtained after powdering & $495 \pm 20$ \\
$99 \pm 3$ & Theoretical APAP mass in the weighted tablet \\
& APAP mass determined with CH-CPE & Recovery (\%) \\
\hline
\end{tabular}

* $3 \%$ error admitted by the European drugs regulation for the commercialization of APAP tablets.

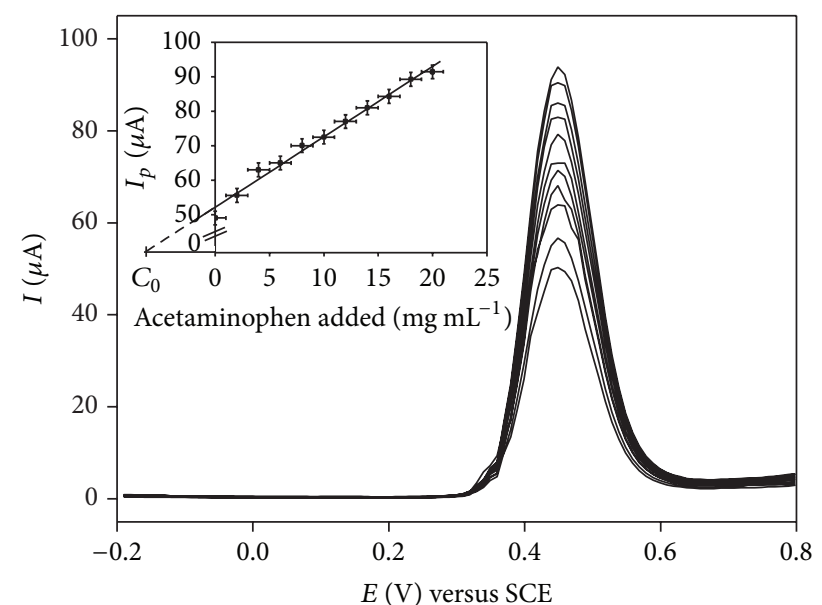

FIGURE 7: SWV curves recorded for the commercial tablet Doliprane 1000 , upon addition of known amounts of APAP in the supporting electrolyte. Insert displays the corresponding calibration curve.

solution did not influence the response of this latter. Likewise, glucose at the same concentration was found to interfere slightly with APAP. The most dramatic effect was noticed with aspartic acid which greatly reduced the SWV signal of APAP when added at the same concentration. This fact leads us to suggest the elimination of aspartic acid from any matrices before the quantification of APAP.

3.9. Analytical Application of CH-CPE to the Determination of APAP in Pharmaceutical Tablets. The sensor based on $\mathrm{CH}-\mathrm{CPE}$ was applied for direct detection of APAP in commercial tablets, Doliprane 500 and Doliprane 1000, using the common analytical method of internal standards. As illustrated in Figure 7, a linear relationship was obtained between the peak intensity (observed at $0.5 \mathrm{~V}$ versus SCE) and concentration of added APAP. It is expressed as $I_{p}(\mu \mathrm{A})$ $=2.04 C\left(\mathrm{mg} \mathrm{L}^{-1}\right)+52\left(R^{2}=0.99\right)$ for Doliprane 1000 and as $I_{p}(\mu \mathrm{A})=1.9 C\left(\mathrm{mg} \mathrm{L}^{-1}\right)+47\left(R^{2}=0.99\right)$ for Doliprane 500 . The obtained results were in the range of the commercial limit of quality admitted by the European drugs regulation (3\%) and the obtained recoveries were $102 \%$ and $99 \%$ for Doliprane
1000 and Doliprane 500, respectively (Table 4). As shown in Table 4 , the recovery amounts of APAP in commercial tablets were in an acceptable range (97\% to 103\%), proving that the proposed sensor and the standard addition method are suitable for the determination of APAP in pharmaceutical formulations.

\section{Conclusions}

This work demonstrates the ability of a CPE chemically modified by coffee husks for the electrochemical determination of acetaminophen in pharmaceutical formulations. The beneficial organophilic effect of coffee husks in the bulk of the carbon paste electrode was first demonstrated towards the accumulation of acetaminophen, using cyclic voltammetry and SWV. It was shown that the process occurring at the modified electrode for acetaminophen is controlled by diffusion. The calibration curve of biosensor showed a linear range from $6.6 \mu \mathrm{M}$ to $0.5 \mathrm{mM}$ with a sensitivity of $0.63 \mu \mathrm{A} \mathrm{mg}^{-1} \mathrm{~L}$ and a detection limit of $6.6 \times 10^{-7} \mathrm{M}(S / N=3)$. The use of the proposed sensor for the determination of APAP in commercial tablets of Doliprane shows an acceptable recovery range from $98 \%$ to $103 \%$. The simplicity and low cost of the proposed method and the performance of the sensor in terms of low detection limit suggest that carbon paste electrodes modified with lignocellulosic materials may be useful for clinical and quality control laboratories.

\section{Competing Interests}

The authors declare that they have no competing interests.

\section{Acknowledgments}

The authors wish to thank R. Mallet (SCIAM, Angers University, France) for recording the FEGSEM images. They also thank the University of Angers (France) for funds allocated to Serge Foukmeniok Mbokou for a scientific stay in France (ARIANES program). Maxime Pontie acknowledges the support of Origalys Electrochem SAS (France) for a travel in Cameroon. 


\section{References}

[1] O. Fatibello-Filho, K. O. Lupetti, and I. C. Vieira, "Chronoamperometric determination of paracetamol using an avocado tissue (Persea americana) biosensor," Talanta, vol. 55, no. 4, pp. 685-692, 2001.

[2] A. Afkhami, H. Khoshsafar, H. Bagheri, and T. Madrakian, "Preparation of $\mathrm{NiFe}_{2} \mathrm{O}_{4}$ /graphene nanocomposite and its application as a modifier for the fabrication of an electrochemical sensor for the simultaneous determination of tramadol and acetaminophen," Analytica Chimica Acta, vol. 831, pp. 50-59, 2014.

[3] H. Beitollahi, J.-B. Raoof, and R. Hosseinzadeh, "Fabrication of a nanostructure-based electrochemical sensor for simultaneous determination of $\mathrm{N}$-acetylcysteine and acetaminophen," Talanta, vol. 85, no. 4, pp. 2128-2134, 2011.

[4] F. L. Martin and A. E. M. McLean, "Comparison of paracetamolinduced hepatotoxicity in the rat in-vivo with progression of cell injury in-vitro in rat-liver slices," Drug and Chemical Toxicology, vol. 21, no. 4, pp. 477-494, 1998.

[5] H. M. Moghaddam, "Electrocatalytic determination of carbidopa and acetaminophen using a modified carbon nanotube paste electrode," International Journal of Electrochemical Science, vol. 6, no. 12, pp. 6557-6566, 2011.

[6] H. Filik, G. Çetintaş, A. Aslihan Avan, S. N. Koç, and I. Boz, "Electrochemical sensing of acetaminophen on electrochemically reduced graphene oxide-nafion composite film modified electrode," International Journal of Electrochemical Science, vol. 8, no. 4, pp. 5724-5737, 2013.

[7] K. G. Kumar and R. Letha, "Determination of Paracetamol in pure form and in dosage forms using N,N-dibromo dimethylhydantoin," Journal of Pharmaceutical and Biomedical Analysis, vol. 15, no. 11, pp. 1725-1728, 1997.

[8] F. A. Mohamed, M. A. AbdAllah, and S. M. Shammat, "Selective spectrophotometric determination of $\mathrm{p}$-aminophenol and acetaminophen," Talanta, vol. 44, no. 1, pp. 61-68, 1997.

[9] M. S. Bloomfield, "A sensitive and rapid assay for 4aminophenol in paracetamol drug and tablet formulation, by flow injection analysis with spectrophotometric detection," Talanta, vol. 58, no. 6, pp. 1301-1310, 2002.

[10] Sirajuddin, A. R. Khaskheli, A. Shah, M. I. Bhanger, A. Niaz, and S. Mahesar, "Simpler spectrophotometric assay of paracetamol in tablets and urine samples," Spectrochimica Acta Part A: Molecular and Biomolecular Spectroscopy, vol. 68, no. 3, pp. 747751, 2007.

[11] J. A. M. Pulgarín and L. F. G. Bermejo, "Flow-injection stoppedflow spectrofluorimetric kinetic determination of paracetamol based on its oxidation reaction by hexacyanoferrate (III)," Analytica Chimica Acta, vol. 333, no. 1-2, pp. 59-69, 1996.

[12] D. Easwaramoorthy, Y.-C. Yu, and H.-J. Huang, "Chemiluminescence detection of paracetamol by a luminol-permanganate based reaction," Analytica Chimica Acta, vol. 439, no. 1, pp. 95100, 2001

[13] W. Peng, T. Li, H. Li, and E. Wang, "Direct injection of urine and determination of acetaminophen by micellar liquid chromatography with a wall-jet cell/carbon fibre microelectrode," Analytica Chimica Acta, vol. 298, no. 3, pp. 415-421, 1994.

[14] M. G. Gioia, P. Andreatta, S. Boschetti, and R. Gatti, "Development and validation of a liquid chromatographic method for the determination of ascorbic acid, dehydroascorbic acid and acetaminophen in pharmaceuticals," Journal of Pharmaceutical and Biomedical Analysis, vol. 48, no. 2, pp. 331-339, 2008.
[15] J. Sun, L. K. Schnackenberg, R. D. Holland et al., "Metabonomics evaluation of urine from rats given acute and chronic doses of acetaminophen using NMR and UPLC/MS," Journal of Chromatography B, vol. 871, no. 2, pp. 328-340, 2008.

[16] S. A. Kumar, C.-F. Tang, and S.-M. Chen, "Electroanalytical determination of acetaminophen using nano- $\mathrm{TiO}_{2} /$ polymer coated electrode in the presence of dopamine," Talanta, vol. 76, no. 5, pp. 997-1005, 2008.

[17] M. Mazloum-Ardakani, H. Beitollahi, M. K. Amini, F. Mirkhalaf, and B.-F. Mirjalili, "A highly sensitive nanostructure-based electrochemical sensor for electrocatalytic determination of norepinephrine in the presence of acetaminophen and tryptophan," Biosensors \& Bioelectronics, vol. 26, no. 5, pp. 2102-2106, 2011.

[18] B. Habibi, M. Jahanbakhshi, and M. H. Pournaghi-Azar, "Differential pulse voltammetric simultaneous determination of acetaminophen and ascorbic acid using single-walled carbon nanotube-modified carbon-ceramic electrode," Analytical Biochemistry, vol. 411, no. 2, pp. 167-175, 2011.

[19] T. Madrakian, E. Haghshenas, and A. Afkhami, "Simultaneous determination of tyrosine, acetaminophen and ascorbic acid using gold nanoparticles/multiwalled carbon nanotube/glassy carbon electrode by differential pulse voltammetric method," Sensors and Actuators B: Chemical, vol. 193, pp. 451-460, 2014.

[20] K. Tyszczuk-Rotko, I. Bęczkowska, M. Wójciak-Kosior, and I. Sowa, "Simultaneous voltammetric determination of paracetamol and ascorbic acid using a boron-doped diamond electrode modified with Nafion and lead films," Talanta, vol. 129, pp. 384391, 2014.

[21] M. E. Ghica, G. M. Ferreira, and C. M. A. Brett, "Poly(thionine)carbon nanotube modified carbon film electrodes and application to the simultaneous determination of acetaminophen and dipyrone," Journal of Solid State Electrochemistry, vol. 19, no. 9, pp. 2869-2881, 2015.

[22] H. Beitollahi and S. Nekooei, "Application of a modified $\mathrm{CuO}$ nanoparticles carbon paste electrode for simultaneous determination of isoperenaline, acetaminophen and $\mathrm{N}$-acetylL-cysteine," Electroanalysis, vol. 28, no. 3, pp. 645-653, 2016.

[23] M. A. Mohammad, H. Laleh, K. Alireza, N. Hossein, and M. Mohsen, "Simultaneous determination of isoproterenol, acetaminophen and folic acid using a novel nanostructurebased electrochemical sensor," Electroanalysis, vol. 26, no. 2, pp. 275-284, 2014.

[24] M. R. Shahmiri, A. Bahari, H. Karimi-Maleh, R. Hosseinzadeh, and N. Mirnia, "Ethynylferrocene-NiO/MWCNT nanocomposite modified carbon paste electrode as a novel voltammetric sensor for simultaneous determination of glutathione and acetaminophen," Sensors and Actuators B: Chemical, vol. 177, pp. 70-77, 2013.

[25] M. H. Mashhadizadeh and F. Rasouli, "Design of a new carbon paste electrode modified with $\mathrm{TiO}_{2}$ nanoparticles to use in an electrochemical study of codeine and simultaneous determination of codeine and acetaminophen in human plasma serum samples," Electroanalysis, vol. 26, no. 9, pp. 2033-2042, 2014.

[26] C. M. Kuskur, B. E. K. Swamy, and H. Jayadevappa, "Electrochemical investigation of paracetamol at poly(glycine) modified carbon paste electrode: a voltametric study,", Journal of Analytical and Bioanalytical Technology, vol. 6, article 260, 2015.

[27] S. Sharifian and A. Nezamzadeh-Ejhieh, "Modification of carbon paste electrode with $\mathrm{Fe}$ (III)-clinoptilolite nano-particles for simultaneous voltammetric determination of acetaminophen 
and ascorbic acid," Materials Science and Engineering C, vol. 58, pp. 510-520, 2016.

[28] R. N. Adams, "Carbon paste electrodes," Analytical Chemistry, vol. 30, no. 9, pp. 1576-1579, 1958.

[29] B. J. Sanghavi and A. K. Srivastava, "Simultaneous voltammetric determination of acetaminophen, aspirin and caffeine using an in situ surfactant-modified multiwalled carbon nanotube paste electrode," Electrochimica Acta, vol. 55, no. 28, pp. 8638-8648, 2010.

[30] I. G. Švegl and B. Ogorevc, "Soil-modified carbon paste electrode: a useful tool in environmental assessment of heavy metal ion binding interactions," Fresenius' Journal of Analytical Chemistry, vol. 367, no. 8, pp. 701-706, 2000.

[31] Z. Aksu, "Application of biosorption for the removal of organic pollutants: a review," Process Biochemistry, vol. 40, no. 3-4, pp. 997-1026, 2005.

[32] W. S. Wan Ngah and M. A. K. M. Hanafiah, "Removal of heavy metal ions from wastewater by chemically modified plant wastes as adsorbents: a review," Bioresource Technology, vol. 99, no. 10, pp. 3935-3948, 2008.

[33] C. P. Nanseu-Njiki, G. K. Dedzo, and E. Ngameni, "Study of the removal of paraquat from aqueous solution by biosorption onto Ayous (Triplochiton schleroxylon) sawdust," Journal of Hazardous Materials, vol. 179, no. 1-3, pp. 63-71, 2010.

[34] M. Akhtar, S. M. Hasany, M. I. Bhanger, and S. Iqbal, "Low cost sorbents for the removal of methyl parathion pesticide from aqueous solutions," Chemosphere, vol. 66, no. 10, pp. 1829-1838, 2007.

[35] A. E. Ofomaja, "Kinetic study and sorption mechanism of methylene blue and methyl violet onto mansonia (Mansonia altissima) wood sawdust," Chemical Engineering Journal, vol. 143, no. 1-3, pp. 85-95, 2008.

[36] P. S. Murthy and M. Madhava Naidu, "Sustainable management of coffee industry by-products and value addition-a review," Resources, Conservation and Recycling, vol. 66, pp. 45-58, 2012.

[37] S. A. Bekalo and H.-W. Reinhardt, "Fibers of coffee husk and hulls for the production of particleboard," Materials and Structures, vol. 43, no. 8, pp. 1049-1060, 2010.

[38] I. Noviandri and R. Rakhmana, "Carbon paste electrode modified with carbon canotubes and poly(3-aminophenol) for voltammetric determination of paracetamol," International Journal of Electrochemical Science, vol. 7, pp. 4479-4487, 2012.

[39] M. Mazloum-Ardakani, H. Beitollahi, M. K. Amini, F. Mirkhalaf, and M. Abdollahi-Alibeik, "New strategy for simultaneous and selective voltammetric determination of norepinephrine, acetaminophen and folic acid using $\mathrm{ZrO}_{2}$ nanoparticlesmodified carbon paste electrode," Sensors and Actuators, B: Chemical, vol. 151, no. 1, pp. 243-249, 2010.

[40] W.-Y. Su and S.-H. Cheng, "Electrochemical oxidation and sensitive determination of acetaminophen in pharmaceuticals at poly(3,4-ethylenedioxythiophene)-modified screen-printed electrodes," Electroanalysis, vol. 22, no. 6, pp. 707-714, 2010.

[41] S.-F. Wang, F. Xie, and R.-F. Hu, "Carbon-coated nickel magnetic nanoparticles modified electrodes as a sensor for determination of acetaminophen," Sensors and Actuators B: Chemical, vol. 123, no. 1, pp. 495-500, 2007.

[42] M. Li and L. Jing, "Electrochemical behavior of acetaminophen and its detection on the PANI-MWCNTs composite modified electrode," Electrochimica Acta, vol. 52, no. 9, pp. 3250-3257, 2007.

[43] A. Ishizu, "Chemical modification of cellulose," in Wood and Cellulosic Chemistry, D. N.-S. Hon and N. Shiraishi, Eds., chapter 16, p. 757, Marcel Dekker, New York, NY, USA, 1991.
[44] S. Tajik, M. A. Taher, and H. Beitollahi, "Application of a new ferrocene-derivative modified-graphene paste electrode for simultaneous determination of isoproterenol, acetaminophen and theophylline," Sensors and Actuators B: Chemical, vol. 197, pp. 228-236, 2014.

[45] M. Mazloum-Ardakani, M. Zokaie, and A. Khoshroo, "Carbon nanotube electrochemical sensor based on and benzofuran derivative as a mediator for the determination of levodopa, acetaminophen, and tryptophan," Ionics, vol. 21, no. 6, pp. 17411749, 2015.

[46] P. J. Van Soest and R. H. Wine, "Use of detergents in the analysis of fibrous feeds. IV. Determination of plant cell wall constituents," Journal of the Association of Official Analytical Chemists, vol. 50, pp. 50-55, 1967.

[47] P. J. Van Soest and R. H. Wine, "Determination of lignin and cellulose in acid detergent fiber with permanganate," Journal of the Association of Official Analytical Chemists, vol. 51, pp. 780784, 1968.

[48] A. J. Bard and L. R. Faulkner, Electrochemical Methods: Fundamentals and Applications, John Wiley \& Sons, New York, NY, USA, 2nd edition, 2001.

[49] F. Le Digabel and L. Avérous, "Effects of lignin content on the properties of lignocellulose-based biocomposites," Carbohydrate Polymers, vol. 66, no. 4, pp. 537-545, 2006.

[50] S. I. Mussatto, L. M. Carneiro, J. P. A. Silva, I. C. Roberto, and J. A. Teixeira, "A study on chemical constituents and sugars extraction from spent coffee grounds," Carbohydrate Polymers, vol. 83, no. 2, pp. 368-374, 2011.

[51] M. Pontié, L. Sikpo, G. Thouand et al., "Direct electroanalysis of p-nitrophenol (PNP) in estuarine and surface waters by a high sensitive type C/p-NiTSPc coating carbon fiber microelectrode (CFME)," Electroanalysis, vol. 23, no. 2, pp. 433-441, 2011.

[52] A. Babaei, A. Dehdashti, and M. Afrasiabi, "Development of a method for a sensitive simultaneous determination of dopamine and paracetamol in biological samples and pharmaceutical preparation," International Journal of Electrochemistry, vol. 2011, Article ID 452629, 6 pages, 2011.

[53] S. M. Ghoreishi, M. Behpour, S. Sadeghzadeh, and M. Golestaneh, "Electrochemical determination of acetaminophen in different pharmaceutical forms with gold nanoparticles carbon paste electrode," Acta Chimica Slovenica, vol. 58, no. 1, pp. 69-74, 2011.

[54] A. Afkhami, H. Khoshsafar, H. Bagheri, and T. Madrakian, "Facile simultaneous electrochemical determination of codeine and acetaminophen in pharmaceutical samples and biological fluids by graphene-CoFe $\mathrm{O}_{4}$ nancomposite modified carbon paste electrode," Sensors and Actuators B: Chemical, vol. 203, pp. 909-918, 2014.

[55] Y. Li and S.-M. Chen, "The electrochemical properties of acetaminophen on bare glassy carbon electrode," International Journal of Electrochemical Science, vol. 7, no. 3, pp. 2175-2187, 2012.

[56] T. M. B. F. Oliveira, M. Fátima Barroso, S. Morais et al., "Biosensor based on multi-walled carbon nanotubes paste electrode modified with laccase for pirimicarb pesticide quantification," Talanta, vol. 106, pp. 137-143, 2013.

[57] C. S. Santos, R. T. Ferreira, C. M. F. Calixto et al., "The influence of organization of LbL films containing a silsesquioxane polymer on the electrochemical response of dopamine," Journal of Applied Electrochemistry, vol. 44, no. 9, pp. 1047-1058, 2014. 

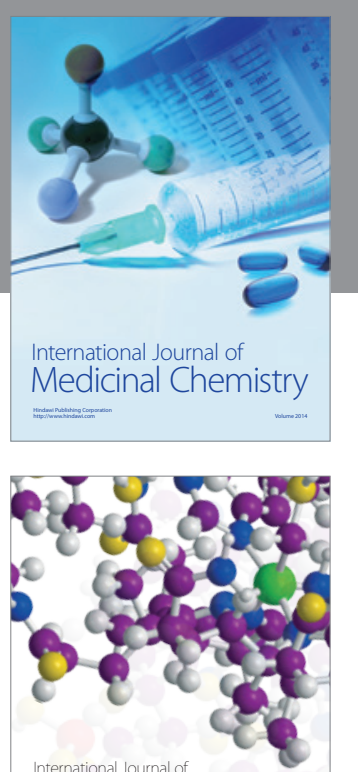

Carbohydrate Chemistry

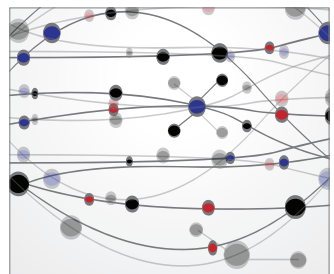

The Scientific World Journal
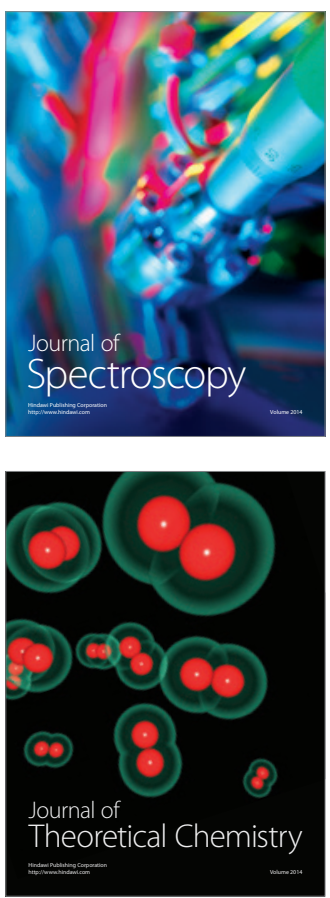
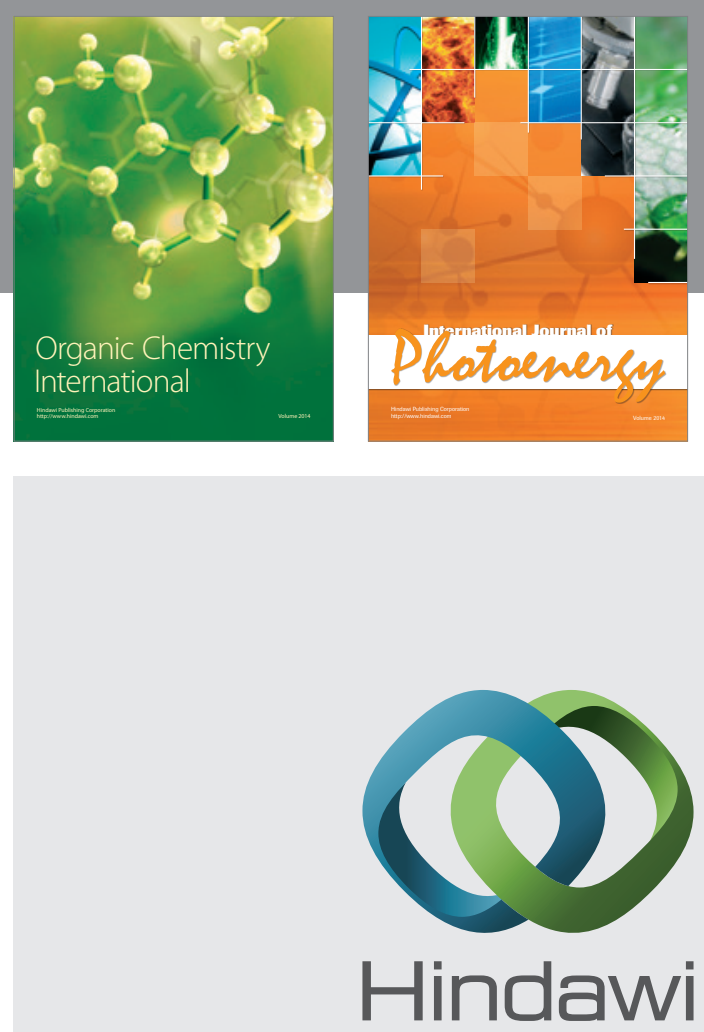

Submit your manuscripts at

http://www.hindawi.com

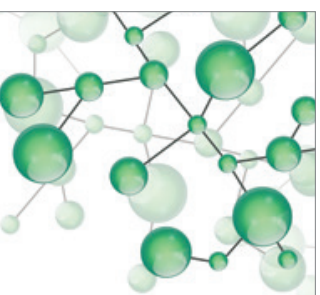

International Journal of

Inorganic Chemistry

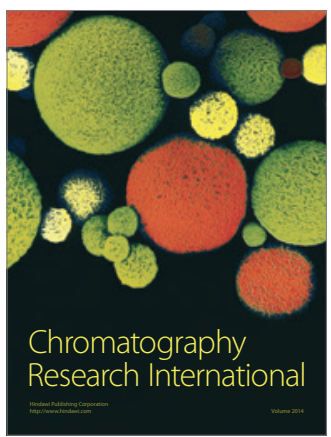

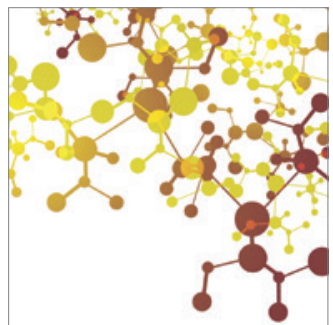

Applied Chemistry
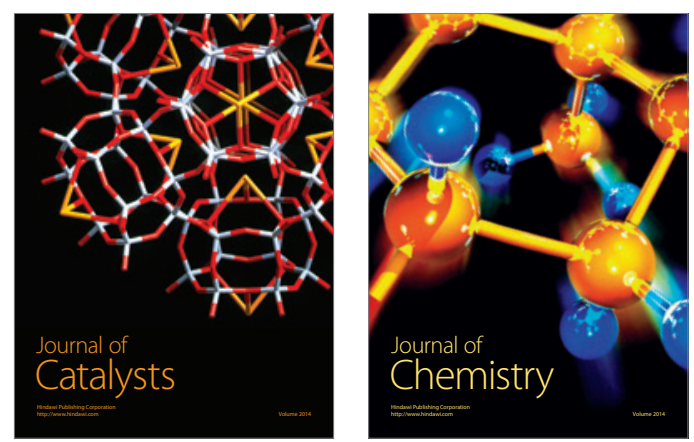
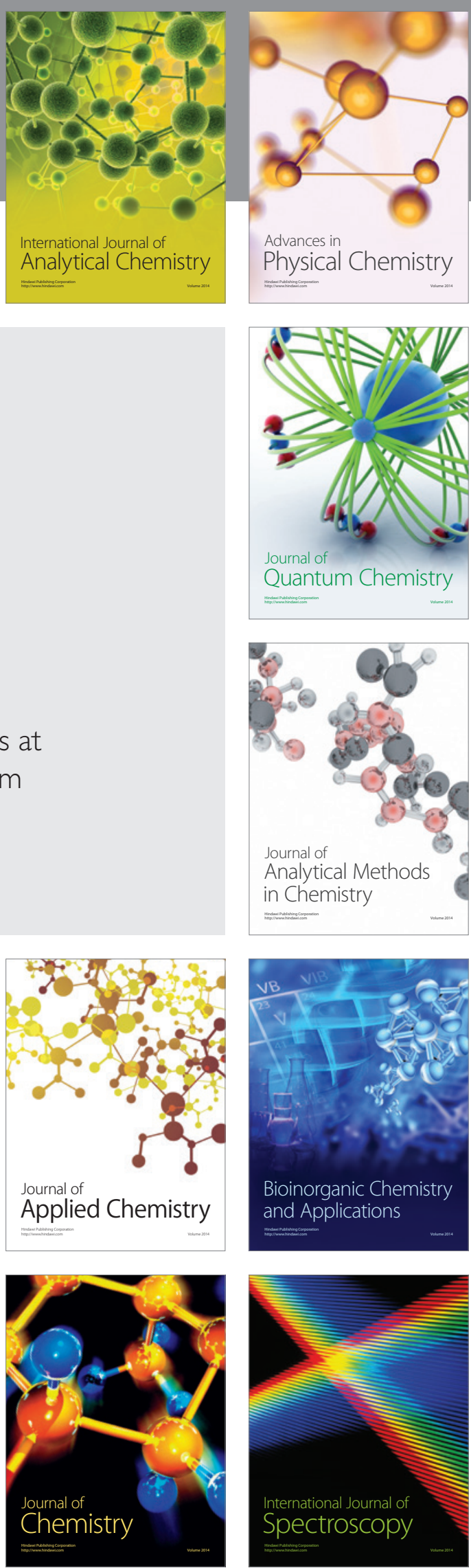